TREE-RING RESEARCH, Vol. 63(1), 2007, pp. 3-14

\title{
TREE-RING-DERIVED PRECIPITATION RECORDS FROM INNER MONGOLIA, CHINA, SINCE A.D. 1627
}

\author{
YU LIU* \\ The State Key Laboratory of Loess and Quaternary Geology \\ The Institute of Earth Environment, Chinese Academy of Sciences \\ Xi' an 710075, China \\ Department of Environment Engineering \\ School of Energy and Power Engineering of Xi' an Jiaotong University \\ Xi' an 710049, China \\ JUNYAN SUN, YINKE YANG, QIUFANG CAI, \\ HUIMING SONG, JIANGFENG SHI \\ The State Key Laboratory of Loess and Quaternary Geology \\ The Institute of Earth Environment, Chinese Academy of Sciences \\ Xi' an 710075, China \\ Graduate School of the Chinese Academy of Sciences, Beijing 100049, China
}

\section{ZHISHENG AN}

The State Key Laboratory of Loess and Quaternary Geology The Institute of Earth Environment, Chinese Academy of Sciences Xi' an 710075, China

and

XUXIANG LI

Department of Environment Engineering

School of Energy and Power Engineering of Xi' an Jiaotong University

Xi' an 710049, China

\begin{abstract}
Two Chinese pine (Pinus tabulaeformis) tree-ring width chronologies up to 375 years long were used to reconstruct rainfall from February to early July for the Wu Dangzhao region and from February to midJuly for the La Madong region, Inner Mongolia, China. The predictor variables account for $44.3 \%$ and $42.7 \%$ of the variance in precipitation, respectively. Both historical records and two other tree-ring based precipitation reconstructions from the environmentally sensitive zone (the northern Helan Mountain range and Baiyinaobao) confirm our results. After applying a 10-year moving average, the trends of four treering based precipitation reconstructions vary synchronously. Periods with below-normal precipitation occurred during the 1720s-1730s, 1740s-1750s, 1790s, early 1810s, late 1830s-1860s, 1880s-1910s, late 1920s-1930s and after the late 1960s-early 1970s. Periods with above-normal precipitation occurred in the 1760 s to early 1770 s, 1820 s to early 1830 s, 1870 s- 1880 s, early 1920 s, 1940 s to early 1960 s, and 1990 s. The late 1920s period was the most severe drought over a broad area in north China in the last 375 years. In contrast, the wettest period was in the late 1990s.
\end{abstract}

Keywords: Inner Mongolia, Pinus tabulaeformis Carriere, tree rings, precipitation reconstruction.

\section{INTRODUCTION}

An environmentally sensitive zone defined by lines of equal precipitation, temperature, and moisture (Zhou 1996; Fu et al. 1998) stretches from

*Corresponding author: liuyu@loess.llqg.ac.cn northeast to southwest China (Figure 1, shaded area in small inset map). This is the transition zone from semi-arid to arid conditions, namely from monsoon to non-monsoon influence, with annual precipitation of 200 to $400 \mathrm{~mm}$ (70-90\% of which is concentrated in the summer) and annual mean 


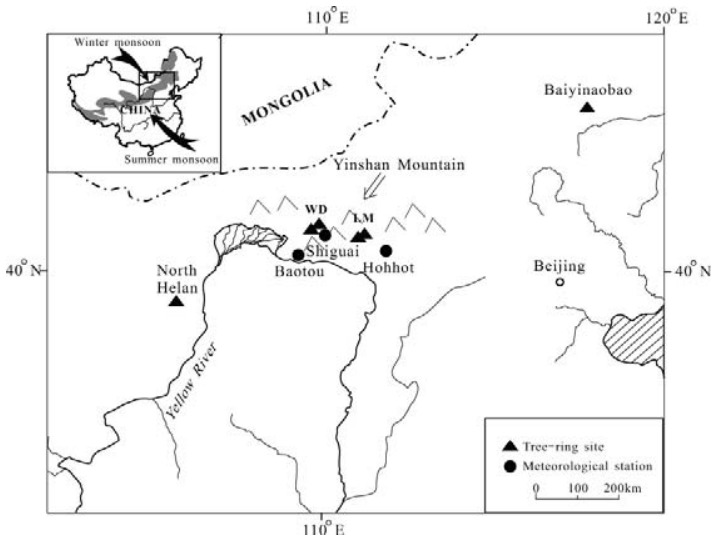

Figure 1. Location of the sampling sites $(\mathbf{\Delta})$, meteorological stations (O) and two other comparison tree-ring sites, Baiyinaobao and the north Helan Mountain. The shaded area in the map of China (inset) indicates the environmentally sensitive zone.

temperature of $5.5^{\circ} \mathrm{C}$ to $8.1^{\circ} \mathrm{C}$. In the area north of $30^{\circ}$, the northwesterly winds are strong and dust storms occur 40 times per year on average with $72 \%$ occurring from March to May (Wang 1997). Seasonally dry and wet conditions alternate associated with the intrusion of dry-cold air masses from high latitudes in winter (the East Asian winter monsoon, EAWM), and warm-humid air masses from the equatorial or low latitude oceans in summer (the East Asian summer monsoon, EASM).

Agriculture is traditionally the primary livelihood in monsoonal China and the harvest is largely affected by rainfall. Unfortunately, frequent drought and flooding caused by strongly varying precipitation can result in the loss of lives and tremendous property damage. To derive reliable scenarios of climate change, it is imperative to understand and predict the climate in the past in China (Fu and Zeng 1997).

Abundant Chinese historical documents provide a wealth of information for paleoclimate research. A 500-year-long series of annual dryness/wetness indices (Academy of Meteorological Science 1982) and cold/warm intervals (Zhang 1996) was generated from the analysis of these documents.

Another high-resolution record that could be used for studying precipitation is found in tree rings. In dry areas where tree growth is limited by precipitation, tree rings can be used to reconstruct rainfall (Till and Guiot 1990; D'Arrigo and Jacoby 1991; Hughes et al. 1994; Jacoby et al. 1999; Touchan et al. 1999; Sheppard et al. 2004; Treydte et al. 2006) to quantify the dry-wet variations of the past. Thus, tree rings offer an excellent opportunity to derive information on the past climate in this sensitive region in China. Such information will be of great value in understanding the natural climatic variations on interannual to multidecadal timescales and could contribute to improved capability to anticipate its future variations.

This paper discusses rainfall series reconstructed from tree rings in central Inner Mongolia. These precipitation reconstructions shed some light on climatic variations over the last 375 years.

\section{DATA AND METHODS}

\section{Sites Descriptions and Sampling}

The two sampling sites, Wu Dangzhao (WD, $40^{\circ} 48^{\prime}-50^{\prime} \mathrm{N}$ and $\left.110^{\circ} 18.5^{\prime}-20.5^{\prime} \mathrm{E}\right)$, and $\mathrm{La} \mathrm{Ma}-$ dong (LM, $40^{\circ} 46^{\prime}-47^{\prime} \mathrm{N}$ and $111^{\circ} 16^{\prime}-17.5^{\prime} \mathrm{E}$ ) are located on the south-facing slopes of the Yin Shan Mountains at the northern margin of the EASM (Figure 1). The elevation of the WD site ranges from $1,500 \mathrm{~m}$ to $1,800 \mathrm{~m}$ whereas the $\mathrm{LM}$ site ranges from $1,300 \mathrm{~m}$ to $1,600 \mathrm{~m}$. The Yin Shan Mountains (2,300 $\mathrm{m}$ at the peak of Mt. Da Qing) stretch from east to west in central Inner Mongolia and form an important boundary between temperate grassland, which is agriculture-pasture land, and desert scrub used as pure rangeland. Severe and frequent droughts are the most serious threat to crops and animal husbandry (Wu 1991).

Because of both natural impacts (such as drought) and human activities (logging and fire), trees are rarely present on the exposed southern slopes of the Yin Shan Mountains, but they are more abundant on the northern slope. At these sites, vegetation is sparse and Chinese pine (Pinus tabulaeformis Carriere) is the dominant tree species, although also some arborvitae (Platycladus orientalis (L.) Franco), juniper (Juniperus rigida Siebold and Zucc), and Asian white birch (Betula platyphylla Sukaczev) occur. The sites are very open, with $30 \mathrm{~m}$ to $100 \mathrm{~m}$ distance between individual trees. The WD site has a nutrient-poor soil 
layer about 5-10 cm deep. At the LM site, most trees grow directly on the rocks. Two increment cores from each of 65 trees were collected from the WD site. The oldest core sampled has 283 annual rings. Two cores from each of 55 trees were collected from the LM site and the oldest core goes back to 1525 A.D. Cores were collected at both sites in the summers of 1997 and 2001 .

\section{Chronology Development}

In the laboratory, tree-ring samples were surfaced, crossdated, and measured following standard practices (Stokes and Smiley 1996). The quality control of crossdating was carried out using COFECHA (Holmes 1983). Cores with any ambiguities of crossdating were excluded from further analysis. The average rates of absent rings in the samples at WD and LM are $3.13 \%$ and $1.16 \%$, respectively.

The individual ring-width measurement series were detrended and standardized to ring-width indices using ARSTAN (Cook and Kairiukstis 1990; Dendrochronology Program Library, http://www. ltrr.arizona.edu/software.html). Undesirable growth trends, related to age and stand dynamics unrelated to climatic variation, were removed from each series during the detrending process. To conserve the maximum common signal at the lowest frequency possible, each ring-width measurement series was standardized conservatively with only negative-exponential or straight-line fitting. The individual index series were combined into a single chronology by computing a bi-weight robust mean. Sub-sample signal strength (SSS) was used to assess the adequacy of replication in the early years of the chronologies (Wigley et al. 1984). To ensure the reliability of the reconstructed climate, we restricted our analysis to the period with SSS of at least 0.75. This threshold corresponds to a minimum sample depth of 2 series (trees) for the WD site. The ring-width chronology from the WD site extends from A.D. 1734 to 2001. Meanwhile a minimum sample depth of 5 series (trees) for the LM site extends from A.D. 1627 to 2001. The statistical features of standard series are listed in Table 1.

The WD chronology is based on 69 cores from 40 trees covering the period A.D. 1719 to 2001.
Table 1. Basic statistical features of the WD and LM standard chronologies.

\begin{tabular}{lcc}
\hline \multicolumn{1}{c}{ Statistic } & LM & WD \\
\hline Standard deviation & 0.44 & 0.52 \\
Mean correlation between all series & 0.33 & 0.62 \\
Expressed population signal (EPS) & 0.82 & 0.97 \\
$\%$ Variance in 1st PC & $36.6 \%$ & $63.37 \%$ \\
SSS period $(>0.75)$ & $1627-2001$ & $1734-2001$ \\
$\%$ missing rings & 1.16 & 3.13 \\
\hline
\end{tabular}

Common interval analyses were performed on 45 series from 33 trees for the period A.D. 1880 to 1987. The LM chronology is based on 60 cores from 50 trees covering the period A.D. 1525 to 2001. Common interval analyses were performed on 38 series from 33 trees for the period A.D. 1837 to 1988.

\section{Meteorological Data}

The Shiguai (1961-1990, 1,100 m elevation at $40^{\circ} 46^{\prime} \mathrm{N}$ and $\left.110^{\circ} 23.5^{\prime} \mathrm{E}\right)$ and Hohhot (1951-2001, $1,063 \mathrm{~m}$ elevation at $40^{\circ} 49^{\prime} \mathrm{N}$ and $\left.111^{\circ} 41^{\prime} \mathrm{E}\right) \mathrm{me}-$ teorological stations were used in the tree-ring climatic response analysis because they are located nearest to the sampling sites and have no missing data. Homogeneity was tested by double-mass analysis, a graphical technique (Kohler 1949), and by the Mann-Kendall (Mann 1945) statistical method. The Baotou (1951-2001) station was used as a reference. The test was done using computer programs in the Dendrochronology Program Library (http:// web.ngdc.noaa.gov/paleo/softlib.html). The results show that Shiguai and Hohhot climate data show no heterogeneity. In this study, we used non-overlapping 10-day mean temperature and total precipitation data from September prior to the growth year to October of the growth year from both the Shiguai and Hohhot stations. Figure 2 shows the seasonal distribution of precipitation for all three stations. It should be noted that the Shiguai station was removed in 1991.

\section{Identification of Climate Response}

Ecological site observations and comparison with instrumental rainfall records (see below) in- 


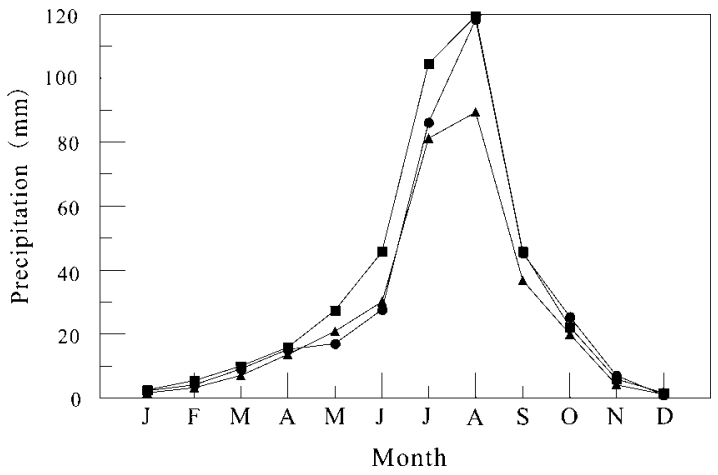

Figure 2. Average monthly precipitation values from the Shig-

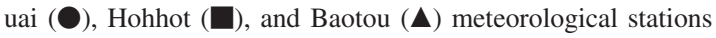
in the region of the sampling sites.

dicate that the ring widths at all study sites are sensitive to precipitation variations. The typical growing season in this area is from late March to early October (Inner Mongolia Forest Agency 1995).

The correlation function analysis results indicate that tree-ring width shows a weak response to temperature and a strong response to precipitation at both sites (Figure 3 ). Tree growth is significantly correlated with precipitation from February to July, with $\mathrm{r}=0.52(\mathrm{n}=51, \mathrm{p}<0.0001)$ for site $\mathrm{LM}$, and $\mathrm{r}=0.51(\mathrm{n}=30, \mathrm{p}<0.004)$ for site WD. Moreover, tree growth is especially influenced by $\mathrm{P}_{27 \mathrm{E}}$, precipitation from February to early July (July 10) at WD, and $\mathrm{P}_{27 \mathrm{M}}$, February to midJuly (July 20) at LM. The highest correlation found between the chronology from WD and total precipitation was from February to early July (July 10) with $r=0.60(n=30, p<0.0001)$, although the individual months of March, April and May correlate only weakly with the index, as seen in Figure 3 . The correlation coefficient between the chronology from LM and total precipitation from February to mid-July (July 20) is also significant with $\mathrm{r}=0.63(\mathrm{n}=51, \mathrm{p}<0.0001)$.

A physiological explanation supports the highly significant correlation values $(\mathrm{r}=0.60$ and 0.63$)$ for the period from February to July (early or mid). In such an arid region, the relationship between tree growth and the total precipitation from spring to early summer can be described as a linear relationship. When temperature rises in spring and
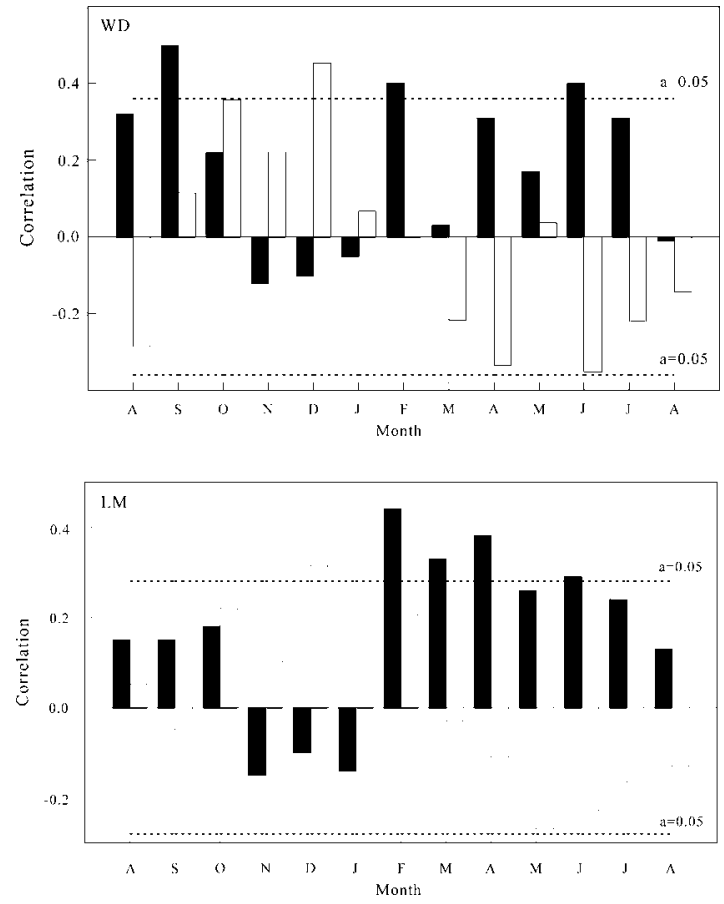

Figure 3. The correlation analysis between ring-width indices and meteorological data. LM vs. Hohhot, and WD vs. Shiguai. The black bar is the precipitation, and the white bar is the temperature. Horizontal lines are the $95 \%$ confidence level.

early summer, the tree needs more water for fast growth, so higher precipitation would be expected to contribute to a wider ring. On the other hand, if water availability decreases under warm conditions in the spring and early summer, tree growth could slow down, producing a narrow ring. In the wet season, however, the relationship between precipitation and ring width becomes less significant and has a non-linear relationship (Shao and Wu 1994). Meteorological research has demonstrated that the greatest amount of rainfall (flooding) occurs during the period of late July to early August (July 21 to August 10) in the study region (Wang 1997). In eastern China, the typical monsoonal region, studies have found relationships between tree-ring width and seasonal precipitation (Liu et al. 1996, 2003, 2004, 2005), but not between ring width and annual precipitation. From field observations and a preliminary analysis we conclude that interannual variability in tree-ring growth in 
the arid study region is most probably controlled by interannual variability in seasonal precipitation.

Generally speaking, February to early summer rainfall is a crucial factor for the commencement of tree growth, formation of new needles, and the effective length of the growing season in the study regions.

\section{PRECIPITATION RECONSTRUCTIONS}

\section{Wu Dangzhao (WD) Rainfall Reconstruction for February to Early July $\left(P_{27 E}\right)$}

According to the correlation results and also considering that the autocorrelation in the STDWD chronology is significant with $\mathrm{r}=0.381$ ( $\mathrm{n}$ $=283$ ), a transfer function between tree-ring width (predictors) and total precipitation of February to early July (predicted) is designed as follows:

$$
\mathrm{P}_{27 \mathrm{E}}=56.6 W_{(t)}-27.5 W_{(t+1)}+74.6
$$

In this regression, $\mathrm{n}=29, \mathrm{r}=0.666, \mathrm{R}^{2}=44.3 \%$, $\mathrm{R}_{\text {adj }}^{2}=40 \%, F=10.35$, standard error $=32.62$, $\mathrm{p}<0.0001$, where $\mathrm{P}_{27 \mathrm{E}}$ is the total precipitation of February to early July (to July 10) and $W_{(t)}$ and $W_{(t+1)}$ are the indices of the $\mathrm{STD}_{(t)}-\mathrm{WD}$ and $\mathrm{STD}_{(t+1)}-\mathrm{WD}$ chronologies, respectively. For the calibration period of $1962-1990$, the equation is highly significant. The predictor variable accounts for $40 \%$ of the variance (adjusted for loss of degrees of freedom) in the precipitation data. Figure 4a shows the comparison of actual and estimated total precipitation of February to early July (July 10) in the WD region for the interval of 1962 1990. The comparisons in Figure 4a reveal that tree rings are more sensitive to capturing dry events than wet events (Fritts 1991). The difficulty in reconstructing extremely wet years is probably related to the fact that tree growth at the sampling sites does not respond positively beyond a certain level of soil moisture (Touchan et al. 1999).

The jackknife replication technique (Mosteller and Tukey 1977) was used to assess the accuracy of the calibrated regression equation because the observation series is short. This procedure could be carried to its limit, where the observations in the calibration period are left out one at a time and calibrations are made on the remainder (Gordon

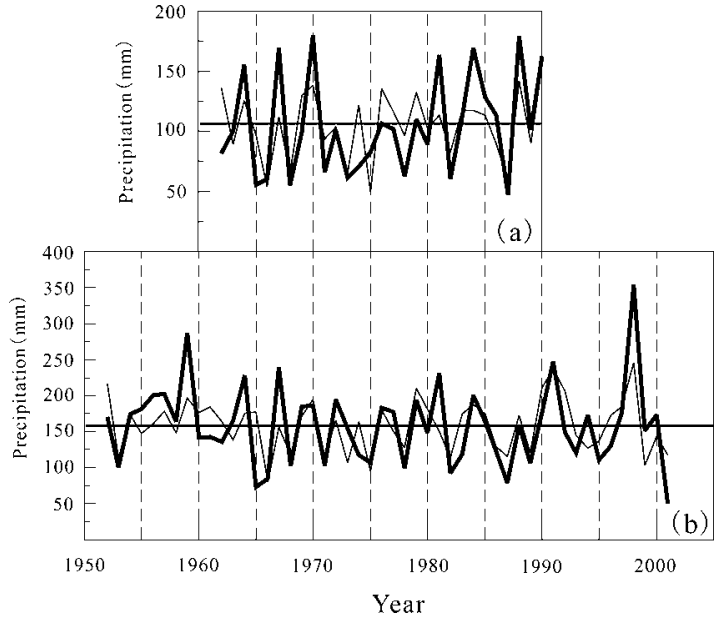

Figure 4. Comparison between observed (thick lines) and treering estimated (thin lines) precipitation (mm). (a) February to early July (to July 10) for WD (1961-1990); (b) February to mid-July (to July 20) for LM (1951-2001). Horizontal lines are the long-term means.

1980). This is also called a "leave-one-out" procedure. The jackknife results revealed that all values of $r, R_{a d j}^{2}$, standard error of estimate, F-value, p-value and Durbin-Watson statistics are close to the values found on the total data set (Table 2, WD part). The small difference between each correlation set shows the stability of the calibration function.

We also used a bootstrap resampling approach (Efron 1979; Young 1994) for the verification tests. This method is used with available observations of a variable containing the necessary information to construct an empirical probability distribution of any statistic of interest, particularly when the data set is small (Cook and Kairiukstis 1990). After 50 iterations, we obtained results equivalent to those of the jackknife method. Again, all values of $r, R_{\mathrm{adj}}^{2}$, standard error of estimate, F-value, p-value and Durbin-Watson statistics are close to the values found on the total data set (Table 2, WD part). Both jackknife and bootstrapping results indicate that the calibration regression model for WD site has relatively stable correlation estimates.

Finally, we also used the sign test $\left(\mathrm{S}_{1}, \mathrm{~S}_{2}\right)$, reduction of error (RE), and product mean (t) (Fritts 1991) to verify the precision and reliability of our 
Table 2. Calibration and verification statistics for WD and LM regression.

\begin{tabular}{|c|c|c|c|}
\hline \multirow{2}{*}{\multicolumn{2}{|c|}{ Calibration }} & \multicolumn{2}{|c|}{ Verification } \\
\hline & & $\begin{array}{c}\text { Jackknife } \\
\text { Mean (range) }\end{array}$ & $\begin{array}{c}\text { Bootstrap (50 iterations) } \\
\text { Mean (range) }\end{array}$ \\
\hline \multicolumn{4}{|l|}{ WD site } \\
\hline$r$ & 0.67 & $0.67(0.64-0.71)$ & $0.65(0.37-0.80)$ \\
\hline $\mathrm{R}_{\text {adj }}^{2}$ & 0.40 & $0.42(0.38-0.49)$ & $0.41(0.10-0.63)$ \\
\hline Standard error of estimate & 32.62 & $32.01(30.52-32.62)$ & $30.32(24.03-35.65)$ \\
\hline$F$ & 10.35 & 20.79 (17.57-26.44) & $22.86(4.34-50.35)$ \\
\hline$p$ & 0.0001 & $0.0001(0.0001-0.0001)$ & $0.002(0.0001-0.046)$ \\
\hline Durbin-Watson & 2.30 & $2.29(1.92-2.48)$ & $2.27(2.08-2.36)$ \\
\hline \multicolumn{4}{|l|}{ LM site } \\
\hline$r$ & 0.65 & $0.65(0.59-0.69)$ & $0.64(0.32-0.79)$ \\
\hline $\mathrm{R}_{\text {adj }}^{2}$ & 0.40 & $0.42(0.34-0.46)$ & $0.40(0.08-0.61)$ \\
\hline Standard error of estimate & 43.55 & $43.09(40.11-43.55)$ & $41.50(30.45-50.73)$ \\
\hline$F$ & 17.51 & $35.08(25.52-42.16)$ & $37.44(5.43-77.54)$ \\
\hline$p$ & 0.0001 & $0.0001(0.0001-0.0001)$ & $0.0006(0.0001-0.024)$ \\
\hline Durbin-Watson & 2.00 & $2.01(1.83-2.19)$ & $1.97(1.86-2.11)$ \\
\hline
\end{tabular}

precipitation reconstructions (Table 3). For the precipitation of February to early July in WD, in general, the verification statistics indicate that the $\mathrm{P}_{27 \mathrm{E}}$ reconstructed data track the independent observation quite well from 1961 to 1990 . The sign test $\mathrm{S}_{1}(\mathrm{n}=21)$ is only significant at the $95 \%$ level ( $\mathrm{n}$ $=21$ ). Thus, the $P_{27 \mathrm{E}}$ reconstruction confidently contains useful palaeoclimatic information. The total precipitation from February to early July for the WD area was reconstructed based on model (1) for the period of A.D. 1734 to 2001 (Figure $5 b)$.

\section{La Madong (LM) Precipitation Reconstruction for February to Mid-July $\left(\mathbf{P}_{27 \mathrm{M}}\right)$}

For the same reason stated above, we also used the standard chronology from LM. It should be noted that autocorrelation in the STD-LM chronology is significant with $\mathrm{r}=0.37$ ( $\mathrm{n}=401)$. Transfer functions were established as:

$$
\mathrm{P}_{27 \mathrm{M}}=12.5 W_{(t)}^{\prime}-3.7 W_{(t+1)}^{\prime}+6.8
$$

In this regression, $\mathrm{n}=50, \mathrm{r}=0.653, \mathrm{R}^{2}=42.7 \%$, $\mathrm{R}_{\mathrm{adj}}^{2}=40.3 \%, \mathrm{~F}=17.51$, standard error $=43.56$, $\mathrm{p}<0.0001$, where $\mathrm{P}_{27 \mathrm{M}}$ is total precipitation of February to mid-July (July 20), and $W_{(t)}^{\prime}$ and
$W_{(t+1)}^{\prime}$ are the indices of the $\mathrm{STD}_{(t)}-\mathrm{LM}$ and $\mathrm{STD}_{(t+1)}-\mathrm{LM}$ chronologies, respectively. For the calibration period 1952-2001, the equation is highly significant. The predictor variable accounts for $40.3 \%$ of the precipitation variance (adjusted for loss of degrees of freedom). Figure $4 \mathrm{~b}$ shows the comparison between observed and tree-ring estimated total precipitation of February to mid-July (July 20) over the LM region for the interval of 1952-2001.

The results of the jackknife and bootstrap tests (Table 2, LM part) show that the calibration regression model for LM site has relatively stable correlation estimates. Statistical characteristics of

Table 3. Statistical characteristics of verification of WD and LM precipitation reconstructions.

\begin{tabular}{ccccc}
\hline & $S_{1}(a, b)$ & $S_{2}(a, b)$ & $t$ & $R E$ \\
\hline LM & $37(30,32)$ & $39(31,33)$ & 5.9 & 0.39 \\
WD & $21(21,23)$ & $23(21,22)$ & 4.2 & 0.42 \\
\hline
\end{tabular}

$a=95 \%$ significant confidence level; $b=99 \%$ level. $R E=$ reduction of error. $S_{1}, S_{2}=$ sign test. $S_{1}$ is the general sign test between observation and reconstruction that measures the associations at all frequencies. $S_{2}$ reflects high-frequency climatic variations derived from first differences; $t=$ product mean test (Fritts 1991). 


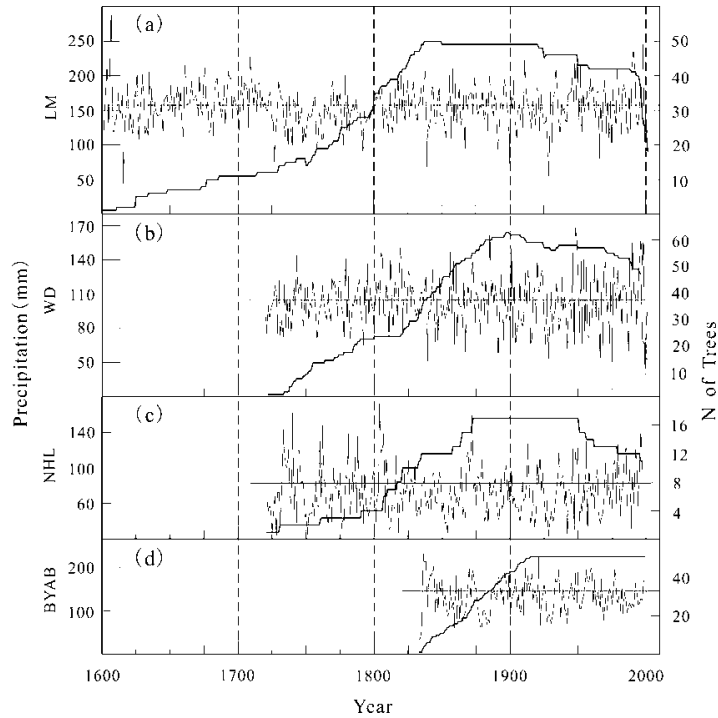

Figure 5. Precipitation changes in four study regions in Northern China. (a) February to mid-July (to July 20) for LM region; (b) February to early July (to July 10) for WD; (c) May to July precipitation for the North Helan Mountains; (d) April to early July (to July 10) precipitation for Baiyinaobao. The superimposed curves show the changing sample size. Horizontal lines represent long-term means.

the sign test $\left(\mathrm{S}_{1}, \mathrm{~S}_{2}\right)$, reduction of error (RE), and product mean $(\mathrm{t})$ for rainfall reconstruction of February to mid-July in LM are listed in Table 3. Based on equation (2), the total precipitation from February to mid-July was reconstructed for the LM area for the period from 1627 (SSS $>0.75$ from 1627) to 2001 (Figure 5a).

\section{DISCUSSION}

\section{Comparison between Precipitation Reconstructions and Historical Documents}

We used a dryness/wetness index derived from historical documentary data to check the reliability of our reconstruction. Chinese historical writings contain abundant descriptions about climatic events that are of considerable value to paleoclimatology. During the 1970s, hundreds of climatologists processed more than 2,200 local annals and many other historical writings nationwide and abstracted more than 2,200,000 characters (data). The degree of annual dryness and wetness (D/W)
Table 4. Five wet/dry classes (P-grade) divided from the two precipitation reconstructions.

\begin{tabular}{|c|c|c|c|c|c|c|}
\hline \multirow{2}{*}{$\begin{array}{l}\mathrm{P}- \\
\text { grade }\end{array}$} & \multirow[b]{2}{*}{ Wet/Dry } & \multirow[b]{2}{*}{ Range } & \multicolumn{2}{|c|}{$\begin{array}{l}\text { No. of } \\
\text { Years }\end{array}$} & \multicolumn{2}{|c|}{$\begin{array}{l}\text { Percentage } \\
\text { of the } \\
\text { Total (\%) }\end{array}$} \\
\hline & & & LM & WD & LM & WD \\
\hline 1 & wettest & $\mathrm{P}_{\mathrm{t}}>\mathrm{P}_{\mathrm{m}}+1.17 \sigma$ & 47 & 33 & 11.7 & 11.7 \\
\hline 2 & wet & $\begin{array}{c}\mathrm{P}_{\mathrm{m}}+0.33 \sigma<\mathrm{P}_{\mathrm{t}} \\
\leq \mathrm{P}_{\mathrm{m}}+1.17 \sigma\end{array}$ & 102 & 70 & 25.5 & 24.9 \\
\hline 3 & normal & $\begin{array}{c}\mathrm{P}_{\mathrm{m}}-0.33 \sigma<\mathrm{P}_{\mathrm{t}} \\
\leq \mathrm{P}_{\mathrm{m}}+0.33 \sigma\end{array}$ & 106 & 70 & 26.5 & 24.9 \\
\hline 4 & dry & $\begin{array}{c}\mathrm{P}_{\mathrm{m}}-1.17 \sigma<\mathrm{P}_{\mathrm{t}} \\
\leq \mathrm{P}_{\mathrm{m}}-0.33 \sigma\end{array}$ & 100 & 71 & 25 & 25.3 \\
\hline 5 & drought & $\mathrm{P}_{\mathrm{t}} \leq \mathrm{P}_{\mathrm{m}}-1.17 \sigma$ & 45 & 37 & 11.3 & 13.2 \\
\hline
\end{tabular}

during the last 510 years was classified into 5 grades (Academy of Meteorological Science 1982): grade 1-very wet, grade 2 -wet, grade 3-normal, grade 4-dry, and grade 5-drought. In Table 4, the definition of the $\mathrm{P}_{\mathrm{m}}$ is precipitation mean, $\sigma$ is the standard deviation, and $\mathrm{P}_{\mathrm{t}}$ is the precipitation in year $t$. LM February to mid-July precipitation $\left(\mathrm{P}_{\mathrm{m}}\right)$ is $154 \mathrm{~mm}$ and $\sigma=31 \mathrm{~mm}$ (A.D. 1601-2001). For WD February to early July precipitation is $103 \mathrm{~mm}$, and $\sigma=24 \mathrm{~mm}$ (A.D. 1720-2001).

We also divided our precipitation reconstructions into five equally probable classes of precipitation-grades (P-grades), based on the standard described in Table 4 . The percentages of wet years (grades $1+2$ ) are $37.2 \%$ for LM and $36.6 \%$ for WD. Dry years (grades $4+5$ ) amount to $36.3 \%$ at LM and $38.5 \%$ at WD and are more frequent than normal years (grade 3) which occur at 26.5\% at $\mathrm{LM}$ and $24.9 \%$ at $\mathrm{WD}$, respectively. In the $\mathrm{WD}$ region, which is $120 \mathrm{~km}$ northwest of LM, the frequency of dry years is higher than that of wet and normal years.

The mean and the range of precipitation from February to mid-July are $154 \mathrm{~mm}$ and 50-354 mm in the LM region, but only $103 \mathrm{~mm}$ and $47-180$ $\mathrm{mm}$ in the more western WD area. The WD region receives much less precipitation than LM. Despite similar variation trends in the reconstructed LM and WD curves, the absolute precipitation amounts are different. 
Many dry and wet years identified in the historical records also emerge in our precipitation reconstructions. Historical records and precipitation reconstructions significantly correlate with Spearman rank correlation coefficient of $r=-0.20$ for LM ( $\mathrm{n}=380,1600-1979$ A.D., $\mathrm{p}<0.0001)$ and $\mathrm{r}=-0.22$ for $\mathrm{WD}(\mathrm{n}=260,1720-1979$ A.D., $\mathrm{p}$ $<0.0001$ ).

Both the precision and resolution of past rainfall series derived from historical documents are likely to be higher after 1900 because many more records are available than in earlier periods (Zhang 1995). The correlations rise to -0.46 for LM (n $=80,1900-1979$ A.D., $p<0.0001)$ and -0.28 for WD ( $\mathrm{n}=80,1900-1979$ A.D., $\mathrm{p}<0.001)$.

We also compared our precipitation reconstructions with local annals from nearby areas (for example Baotou city, $30 \mathrm{~km}$ south of WD, and Hohhot city, $20 \mathrm{~km}$ east of LM). Some severe drought years in these historical records emerge in the two precipitation reconstructions. The years with precipitation of February to early July (or mid-July) lower than $\mathrm{P}_{\mathrm{t}} \leq \mathrm{P}_{\mathrm{m}}-1.17 \sigma$ are described as "severe drought" in original documents (Institute of Meteorology of Inner Mongolia 1975; Council of Inner Mongolia 1976). Examples are given in Table 5 . We should note that for the reasons stated above, many drought years appear in the precipitation reconstructions but not in the historical documents. Almost all severe drought years mentioned in the historical documents correspond to low precipitation years in the precipitation reconstructions. The year 1883 was an exception. It was recorded as "severe drought in Baotou and Hohhot." However, in two tree-ring based precipitation reconstructions no drought is evident. Rainfall in WD was $100 \mathrm{~mm}$ corresponding to normal precipitation (grade 3). Precipitation in LM was 169 $\mathrm{mm}$, and was classified as "wet" (grade 2). This discrepancy points to an error that probably occurred during the translation of the historical document, which emphasizes the need to exercise caution when using historical documents.

\section{Comparison with other Precipitation Reconstructions}

As mentioned above, the environmentally sensitive zone with annual precipitation between 200-
Table 5. The correspondence between years with reconstructed low precipitation from February to early July (or mid July) and documented drought years.

\begin{tabular}{|c|c|c|c|}
\hline \multirow[b]{2}{*}{ Year } & \multicolumn{2}{|c|}{$\begin{array}{c}\text { Reconstructed } \\
\text { Precipitation (mm) }\end{array}$} & \multirow[b]{2}{*}{ Document Descriptions } \\
\hline & $\begin{array}{c}\text { WD } \\
\text { (P-grade) }\end{array}$ & $\begin{array}{c}\text { LM } \\
(\text { P-grade })\end{array}$ & \\
\hline 1750 & $93(4)$ & $109(5)$ & severe drought in Baotou \\
\hline 1758 & $70(5)$ & $92(5)$ & $\begin{array}{l}\text { severe drought in Baotou and } \\
\text { Hohhot, no rainfall for the } \\
\text { whole year, nothing could be } \\
\text { eaten except bark and grass } \\
\text { roots, people even ate each } \\
\text { other }\end{array}$ \\
\hline 1777 & $92(4)$ & $118(4)$ & severe drought \\
\hline 1800 & $75(4)$ & $119(4)$ & severe drought in Baotou \\
\hline 1877 & $99(3)$ & $144(4)$ & severe drought in Baotou and \\
\hline 1878 & $74(5)$ & $158(3)$ & $\begin{array}{l}\text { Hohhot for two years, wheat } \\
\text { was as precious as pearls }\end{array}$ \\
\hline 1883 & $100(3)$ & $158(3)$ & $\begin{array}{l}\text { severe drought in Baotou and } \\
\text { Hohhot }\end{array}$ \\
\hline 1841 & $55(5)$ & $93(5)$ & $\begin{array}{l}\text { severe drought in Baotou and } \\
\text { Hohhot for several years, no } \\
\text { rainfall, cannot plant, no har- } \\
\text { vest, nothing left in the food } \\
\text { bank, countless people died }\end{array}$ \\
\hline 1905 & $80(4)$ & $110(5)$ & severe drought in Baotou \\
\hline 1926 & $65(5)$ & $132(4)$ & $\begin{array}{l}\text { severe drought in Inner Mongolia } \\
\text { on large scale }\end{array}$ \\
\hline 1928 & $53(5)$ & $86(5)$ & $\begin{array}{l}\text { severe drought in Inner Mongolia } \\
\text { on large scale }\end{array}$ \\
\hline 1929 & $75(5)$ & $54(5)$ & $\begin{array}{l}\text { severe drought in Inner mongolia } \\
\text { on large scale for four years (in } \\
\text { north China), nothing in the } \\
\text { field; especially in } 1928 \text {, which } \\
\text { had no rain for spring and sum- } \\
\text { mer, nothing grew, livestock } \\
\text { starved to death }\end{array}$ \\
\hline 1941 & $95(4)$ & $135(4)$ & severe drought in Baotou \\
\hline 1942 & $60(5)$ & $133(4)$ & severe drought in Baotou \\
\hline
\end{tabular}

$400 \mathrm{~mm}$ stretches from northeast to southwest of China. We compared our rainfall reconstructions in this paper with two other annual-resolution precipitation reconstructions. One is from the northern Helan Mountain (NHL), 400 km west of our study area. May to July precipitation reconstruction (Figure 5c) from this site is based on Chinese pine tree-ring width for the period A.D. 1726 to 1997 (Liu et al. 2004). The other series is from Baiyinaobao (BYAB), $600 \mathrm{~km}$ east of LM, in Inner Mongolia (Liu et al. 2003). The total precipi- 
Table 6. Correlations between rainfall reconstructions from LM, WD, Baiyinaobao (BYAB), and northern Helan Mountains (NHL).

\begin{tabular}{|c|c|c|c|c|c|c|}
\hline & \multicolumn{3}{|c|}{$\begin{array}{l}\text { Original Series } \\
\qquad r(\mathrm{~N}, p)\end{array}$} & \multicolumn{3}{|c|}{$\begin{array}{c}\text { After 10-year Smoothing } \\
r\end{array}$} \\
\hline & LM & WD & BYAB & LM & WD & BYAB \\
\hline WD & $0.62(282,0.0001)$ & & & 0.60 & & \\
\hline BYAB & $0.28(163,0.0001)$ & $0.15(163,0.06)$ & & 0.14 & 0.13 & \\
\hline NHL & $0.29(277,0.0001)$ & $0.37(277,0.0001)$ & $0.28(161,0.0001)$ & 0.24 & 0.32 & 0.11 \\
\hline
\end{tabular}

tation from April to early July (July 10) was reconstructed using Picea koraiensis tree-ring width data (Figure 5d).

Precipitation changes at all four sites in the environmentally sensitive zone in northern China are shown in Figure 5. Many local-scale variations can be found in all series. Except for the low correlation between WD and BYAB (Table 6), extreme wet and dry events correspond in many cases, like

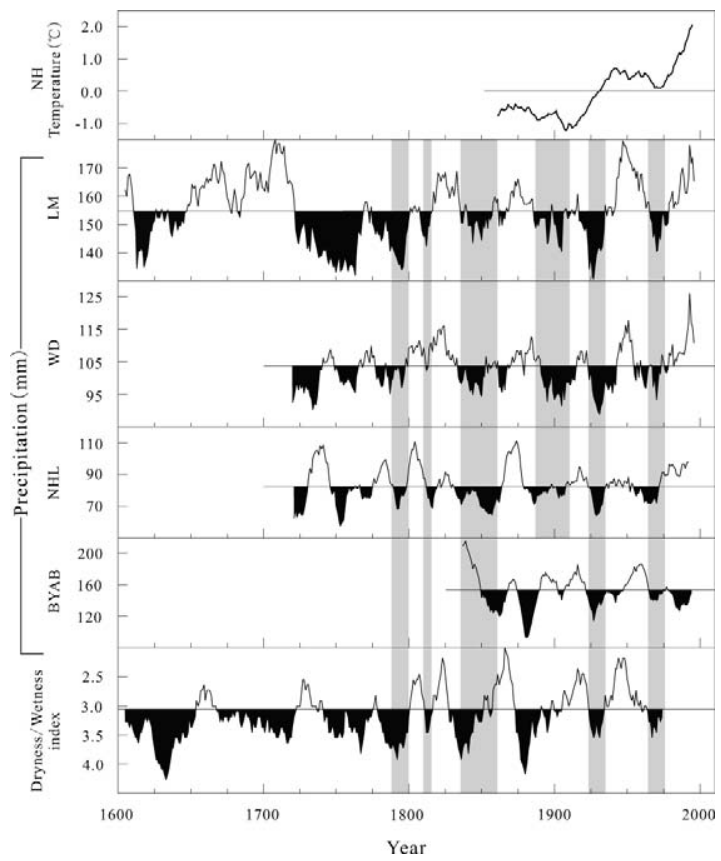

Figure 6. Comparison of dryness/wetness indices and precipitation reconstruction from LM, WD, north Helan Mountains, and Baiyinaobao on decadal to multi-decadal time scales using a 10-year moving average. The top panel is the Northern Hemisphere temperature curve (Folland et al. 2001) after a 10-year moving average. Horizontal lines are the means. the severe droughts in $1792,1839,1867,1900$, 1928-1929, and 1966. This indicates that the same climatic events affect the precipitation from February to July in a large region in north China. The trees we selected responded synchronously to these large-scale climatic variations.

This comparison could also indicate a spatial and temporal connection of spring to early summer climatic condition from the northeast to the southwest along the environmentally sensitive zone.

Rotated empirical orthogonal function (REOF) analysis on these four series revealed that all treering based precipitation reconstructions have the same phases. The results demonstrate the existence of spatially coherent modes of precipitation variations in the LM, WD, Baiyinaobao, and northern Helan Mountains, which reflect large-scale modes of climate forcing on tree growth.

\section{Decadal to Multi-Decadal Variations of Precipitation Reconstructions}

To examine the climatic variations at decadal to multi-decadal time scales, the four reconstructed precipitation series and the dryness-wetness indices were smoothed by a 10 -year moving average (Figure 6). The resulting long-term trends of the four tree-ring based precipitation reconstructions vary almost synchronously, in spite of some low correlations between them (Table 6). The correlations between LM and WD and the dryness/wetness index, become slightly higher than those comparing the original series, with an r-value of 0.25 for $\mathrm{LM}(\mathrm{n}=370, \mathrm{p}<0.01)$ and 0.24 for WD $(\mathrm{n}=250, \mathrm{p}<0.01)$. However, trends of opposite sign occur during the period 1860 to 1870 . 
LM and WD display a relatively wet period, but the dryness/wetness series shows a relatively dry period.

Periods with below normal precipitation occurred during the 1720s-1730s, 1740s-1750s, 1790 s, early 1810s, 1830s-1860s, 1880s-1910s, late 1920s-1930s and after the late 1960s-early 1970s. Periods with above normal precipitation occurred in the 1760s-early 1770s, 1820s-early 1830s, 1870s-1880s, late 1910s-early 1920s, 1940s-early 1960s, and 1990s. Since 1880, the variation trends of precipitation are in phase with the precipitation variations in northeast and northwest China (Qian and Zhu 2001).

Dry intervals occurred in the late 1920s-1930s and late 1960s, and wet periods in late 1910s-early 1920s and 1940s-early 1960s. Precipitation in WD, LM, and the north Helan Mountains increases since the 1970s. Except for Baiyinaobao, they display an increasing trend similar to the Northern Hemisphere temperature curve (Folland et al. 2001). The precipitation may be increasing as the result of rising Northern Hemisphere temperatures (Figure 6). The late 1990s had the highest precipitation in the WD region of the last 268 years (Figure 6).

Another striking feature is the late 1920s' severe drought event, which is displayed in all smoothed curves (Figure 6). In LM, it was the period with the lowest rainfall in the past 375 years, and the lowest precipitation in WD for last 268 years. In the north Helan Mountains and Baiyinaobao, this period exhibited a significant precipitation reduction.

\section{CONCLUSIONS}

Our results show that there is great potential for reconstructing precipitation in the environmentally sensitive zone in north China with tree rings. Using Chinese pine ring-width data, rainfall from February to early July for the Wu Dangzhao region and from February to mid-July for the La Madong region, Inner Mongolia, China, was reconstructed. The explained variances account for $44.3 \%$ and $42.7 \%$ of early summer precipitation, respectively. Many dry (or drought) and wet years in our pre- cipitation reconstructions could be identified in the historical records.

In general, wide rings correspond to high precipitation from February to July (higher than the long-term mean). In contrast, narrow rings are associated with low rainfall from February to July and extended dry (or drought) events.

Our new precipitation reconstructions show great similarity with earlier precipitation reconstruction from the same region, especially in documenting major drought events. Most notably, the late 1920s, displayed in all smoothed curves, was the most severe drought event in a broad area in north China for the last 400 years (Liang et al. 2003, 2004, 2006; Wang et al. 2004; Li et al. 2006). In the 1990s, precipitation from February to July increased in the study area. The extremely wet year 1998 caused tremendous property damage, and $2 / 3$ of the provinces in China suffered from severe flooding (Liu et al. 2005).

After applying a 10-year moving average, the trends of four tree-ring based precipitation reconstructions vary almost synchronously. Periods with below normal precipitation could be found over the 1720s-1730s, 1740s-1750s, 1790s, early $1810 \mathrm{~s}$, late $1830 \mathrm{~s}-1860 \mathrm{~s}, 1880 \mathrm{~s}-1910 \mathrm{~s}$, late 1920s-1930s and after the late 1960s-early 1970s, while periods with above normal precipitation occurred over the 1760s-early 1770s, 1820s-early 1830 s, 1870s-1880s, early 1920s, 1940s to early 1960s, and 1990s.

\section{ACKNOWLEDGMENTS}

We thank Li Qiang, Hao Wenjun, Li Yingxin, Robert Lofgren, Limin Ma for their great help. We also thank two anonymous reviewers who commented on an earlier version of the manuscript. This research was supported by grants from the Chinese NSF (No. 40525004, 40531003) and the National Basic Research Program of China (No. 2006CB400503, 2004CB720206), and Chinese NSF (No. 40121303, 90211018).

\section{REFERENCES CITED}

Academy of Meteorological Science, 1982. Yearly Charts of Dryness/Wetness in China for the Last 500-Year Period. China Cartographic Publishing House, Beijing. 
Cook, E. R., and L. A. Kairiukstis, 1990. Methods of Dendrochronology. Kluwer Academic Publishers, Dordrecht.

Council of Inner Mongolia, 1976. The History of Calamity in Inner Mongolia. Unpublished report. Hohhot, China.

D’Arrigo, R. D., and G. C. Jacoby, 1991. A 1000-year record of winter precipitation from northwestern New Mexio, USA: a reconstruction from tree-rings and its relation to EL Nino and the Southern Oscillation. The Holocene 2:95-101.

Efron, B., 1979. Bootstrap methods: another look at the jackknife. Annals Statistics 7:1-26.

Folland, C. K., T. R. Karl, J. R. Christy, R. A. Clarke, G. V. Gruza, J. Jouzel, M. E. Mann, J. Oerlemans, M. J. Salinger, and S. W. Wang, 2001. Observed climate variability and change. In Climate Change, edited by J. T. Houghton, Y. Ding, D. J. Griggs, M. Noguer, P. J. Van der Linden, X. Dai, K. Maskell, and C. A. Johnson, pp. 99-181. Cambridge University Press, Cambridge.

Fritts, H. C., 1991. Reconstructing Large-scale Climatic Patterns from Tree-Ring Data. The University of Arizona Press, Tucson.

Fu, C., and Z. Zeng, 1997. Monsoon regions: the areas with the largest precipitation variability in the world. Chinese Science Bulletin 42(21):2306-2309.

Fu, C., H. Wei, and M. Chen, 1998. Evolution of summer monsoon rain belts over East China in a regional climate model. Atmospherica Sinica 22:522-534.

Gordon, G. A., 1980. Verification of dendroclimatic reconstructions. In Climate from Tree Rings, edited by M. K. Hughes, P. M. Kelly, J. R. Pilcher, and V. C. Lamarche Jr., pp. 5861. Cambridge University Press, Cambridge, UK.

Holmes, R. L., 1983. Computer-assisted quality control in treering dating and measurement. Tree-Ring Bulletin 43:69-78.

Hughes, M. K., X. Wu, X. Shao, and G. M. Garfin, 1994. A preliminary reconstruction of rainfall in north-central China since A. D. 1600 from tree-ring density and width. Quaternary Research 42(1):88-99.

Inner Mongolia Forest Agency, 1995. Annual Report of Inner Mongolia Forest. Unpublished report, Hohhot, China.

Institute of Meteorology of Inner Mongolia, 1975. Chronology of Meteorological Calamity for Inner Mongolia and its Adjacent Regions. Unpublished report, Hohhot, China.

Jacoby, G. C., R. D. D’Arrigo, N. Pederson, B. Buckley, C. Dugarjav, and R. Mijiddorj, 1999. Temperature and precipitation in Mongolia based on dendroclimatic investigations. IAWA 20:339-350.

Kohler, M. A., 1949. On the use of double-mass analysis for testing the consistency of meteorological records and for making required adjustments. Bulletin of the American Meteorological Society 30:188-189.

Li, J., F. Chen, E. R. Cook, X. Gou, and Y. Zhang, 2006. Drought reconstruction for north central China from tree rings: the value of the Palmer drought severity index. International Journal of Climatology, doi: 10.1002/joc.1450.

Liang, E., X. Liu, Y. Yuan, N. Qin, X. Fang, L. Huang, H. Zhu, L. Wang, and X. Shao, 2006. The 1920s drought recorded by tree rings and historical documents in the semiarid and arid areas of northern China. Climatic Change 79: 403-432, doi: 10.1007/s10584-006-9082-x.
Liang, E., X. Shao, and L. Huang, 2004. The 1920s drought recorded by tree rings in central-Northwest China. Progress in National Science 4:469-474.

Liang, E., X. Shao, Z. Kong, and J. Lin, 2003. The extreme drought in the 1920s and its effect on tree growth deduced from tree ring analysis: A case study in North China. Annals of Forest Sciences 60:145-152.

Liu, Y., Q. Cai, W. K. Park, Z. An, and L. Ma, 2003. Tree-ring precipitation records from Baiyinaobao, Inner Mongolia, China since A.D. 1838. Chinese Science Bulletin 48(11): $1140-1145$.

Liu, Y., Q. Cai, J. Shi, M. K. Hughes, J. E. Kutzbach, Z. Liu, F. Ni, and Z. An, 2005. Seasonal precipitation in the southcentral Helan mountain region, China, reconstructed from tree-ring width for the past 224 years. Canadian Journal of Forest Research 35(10):2403-2412.

Liu, Y., J. Shi, V. Shishov, E. Vaganov, Y. Yang, Q. Cai, J. Sun, L. Wang, and I. Djanseitov, 2004. Reconstruction of May-July precipitation in the north Helan Mountain, Inner Mongolia since A.D. 1726 from tree-ring late-wood widths. Chinese Science Bulletin 49(4):405-409.

Liu, Y., X. Wu, S. W. Leavitt, and M. K. Hughes, 1996. Stable carbon isotope in tree-rings from Huangling, China and climate variation. Science in China 39:152-160.

Mann, H. B., 1945. Non-parametric test against trend. Econometrika 13:245-259.

Mosteller, F., and J. W. Tukey, 1977. Data Analysis and Regression. Addison-Wesley Publishing Company, Massachusetts.

Qian, W., and Y. Zhu, 2001. Climate change in China from 1880 to 1998 and its impact on the environmental condition. Climatic Change 50:419-444.

Shao, X., and X. Wu, 1994. Radial growth of Huashan pine and its response to climate. The Journal of Chinese Geography 4(3/4):88-102.

Sheppard, P. R., P. E. Tarasov, L. J. Graumlich, K. U. Heussner, M. Wagner, H. Osterle, and L. G. Thompson, 2004. Annual precipitation since 515 B.C. reconstructed from living and fossil juniper growth of northeastern Qinghai Province, China. Climate Dynamics 23:869-881.

Stokes, M. A., and T. L. Smiley, 1996. An Introduction to TreeRing Dating. University of Arizona Press, Tucson.

Till, C., and J. Guiot, 1990. Reconstruction of precipitation in Morocco since 1100 A.D. based on Cedrus atlantica treering widths. Quaternary Research 33:337-351.

Touchan, R., D. M. Meko, and M. K. Hughes, 1999. A 396year reconstruction of precipitation in southern Jordan. Journal of the American Water Resources Association 35(1):4959.

Treydte, K. S., G. H. Schleser, G. Helle, D. C. Frank, M. Winiger, G. H. Haug, and J. Esper, 2006. The twentieth century was the wettest period in northern Pakistan over the past millennium. Nature 440:1179-1181.

Wang, C., 1997. Important Climatic Changes in Inner Mongolia. China Meteorological Press, Beijing.

Wang, T., B. Yang, A. Bräuning, and D. Xia, 2004. Decadalscale precipitation variations in arid and semiarid zones of 
northern China during the last 500 years. Chinese Science Bulletin 49(8):842-848, doi: 10.1360/03wd0609.

Wigley, T. M. L., K. R. Briffa, and P. D. Jones, 1984. On the average value of correlation time series, with applications in dendroclimatology and hydrometeorology. Journal of Climate and Applied Meteorology 23:201-213.

Wu, H., 1991. Major Climatic Disaster in Inner Mongolia, China (1947-1987). China Meteorological Press, Beijing.

Young, G. A., 1994. Bootstrap: more than a stab in the dark. Statistical Science 9(3):382-415.
Zhang, D., 1995. High resolution records available from Chinese historical documents. Quaternary Sciences 1:75-81.

Zhang, P., 1996. Cold/warm variation in China since 500 B.P. In Climate of China and Sea-Level Variation and Their Trends and Influences, edited by P. Zhang, pp. 345-351. Shandong Science and Technology Press, Ji'nan.

Zhou, W., 1996. Monsoon Variation in Environmentally Sensitive Zone in China and ${ }^{14} \mathrm{C}$ Chronology. Ph.D. dissertation, Northwest University, Xi'an.

Received 13 May 2006; accepted 27 March 2007. 